\title{
New metal-catalyzed carbocyclization reactions for the construction of complex natural products
}

\author{
P. Andrew Evans, * Erich W. Baum, Aleem N. Fazal, Kwong Wah Lai, \\ John E. Robinson, and James R. Sawyer \\ Department of Chemistry, Indiana University, Bloomington, Indiana 47405 \\ E-mail:paevans@indiana.edu
}

\begin{abstract}
The chemo- and stereoselective aspects of the rhodium-catalyzed $[m+n+o]$ carbocyclization reactions of carbon and heteroatom tethered 1,6-enynes with dienes and alkynes are described. The inter- and intramolecular rhodium-catalyzed [4+2+2] carbocyclization reactions provide a convenient and highly diastereoselective approach to bicyclooctanoids, in which the intramolecular version utilizing a temporary silicon-tether circumvents the issues of poor selectivity and reactivity with substituted dienes. The crossed intermolecular rhodium-catalyzed $[2+2+2]$ carbocyclization reaction provides a convenient approach to bicyclohexadienes, in which the regio- and enantioselective variant addresses the challenges with the regiochemical incorporation of unsymmetrical alkynes.
\end{abstract}

Keywords: Carbocyclization, diastereoselectivity, enantioselective, metallacycles, polycyclic, rhodium-catalyzed

\section{Contents}

1. Rhodium-Catalyzed [4+2+2] Carbocyclization Reactions

2. Diastereoselective Rhodium-Catalyzed [4+2+2] Carbocyclization Reactions

3. Intermolecular Silicon-Tethered Rhodium-Catalyzed [4+2+2] Cycloisomerization Reactions

4. Crossed Intermolecular Rhodium-Catalyzed [2+2+2] Carbocyclization Reactions

5. Regio- and Enantioselective Intermolecular Rhodium-Catalyzed [2+2+2] Carbocyclization Reactions 


\section{Introduction}

The complex polycyclic diterpenes and sesquiterpenes 1-6, which are representative of a larger class of natural products, can be envisioned has having striking structural homology both in terms of their architecture and stereochemistry. ${ }^{1,2}$ For example, compounds 1-3 each have a 5,8bicyclic core, which is decorated with an array of hetero- and carbocyclic rings; whereas the 4-6 have a 5,6-bicyclic core, with annulated lactones and/or cyclic ether, wherein the degree of oxygenation provides the greatest structural diversity. The structural similarities provided the impetus to develop the following metal-catalyzed higher-order carbocyclization reactions that represent an enabling methodology for the expeditious synthesis of these types of natural products.

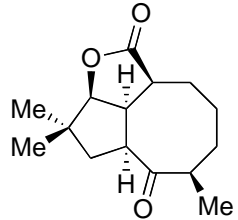

Asteriscanolide (1)

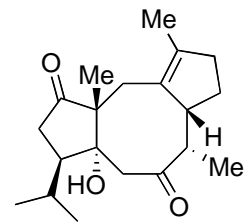

Roseadione (2)

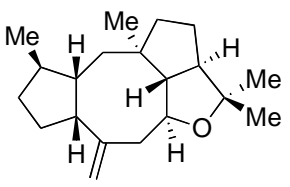

Epoxydictymene (3)

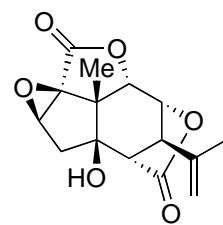

Picrotoxinin (4)

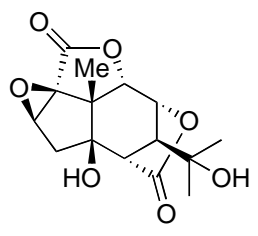

Picrotin (5)

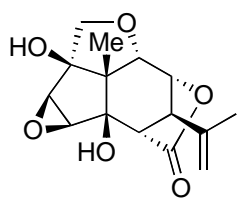

Corianin (6)

We envisioned that both classes of natural products would be derived from a suitably functionalized 1,6-enyne through the requisite transition metal-catalyzed $[m+n+o]$ carbocyclization reaction. ${ }^{3}$ These transformations represent powerful methods for the construction of complex polycyclic systems, since they enable reactions that are generally not accessible through classical pericyclic reactions. Hence, the metal-catalyzed $[4+2+2]$ and $[2+2+2]$ carbocyclization reactions of the 1,6-enyne $\mathbf{i}$ should furnish the octanoid ii and cyclohexadiene iii derivatives that are present in the diterpenes and sesquiterpenes (vide supra). ${ }^{4,5}$ The following discussion represents a summary of the invited seminar presented at the $20^{\text {th }}$ ICHC meeting in Palermo on August 2, 2005.
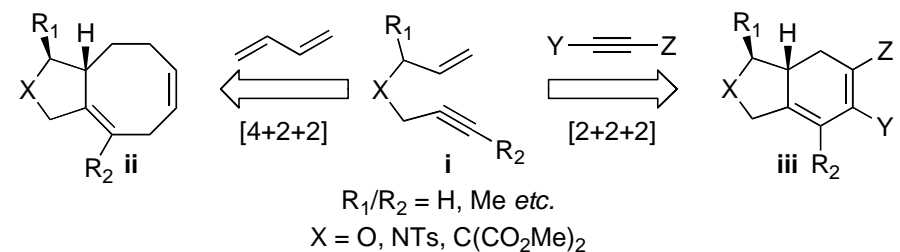

$$
\mathrm{X}=\mathrm{O}, \mathrm{NTs}, \mathrm{C}\left(\mathrm{CO}_{2} \mathrm{Me}\right)_{2}
$$

Figure 1. Divergent synthetic strategy for the construction of the diterpenes and sesquiterpenes 1-6. 


\section{Rhodium-Catalyzed $[4+2+2]$ Carbocyclization Reactions}

We envisioned that the metal-catalyzed intermolecular [4+2+2] cycloaddition of the 1,6-enyne derivatives $\mathbf{i}$ with 1,3-butadiene would facilitate the construction of bicyclic eight-membered hetero- and carbocycles ii in accord with the mechanistic hypothesis outlined in Scheme 1. ${ }^{6-8}$ Complexation of the tethered 1,6-enyne and 1,3-butadiene with the rhodium catalyst forms the metal-complex $\mathbf{A}$, which upon oxidative coupling should afford the metallacycle $\mathbf{B}$, formally a 14-electron Rh(III)-complex. Coordination of an additional butadiene ligand in $\eta^{2}$-fashion will lead to complex $\mathbf{C}$, which should lead to the formation of the [4+2+2] carbocyclization adduct ii. The merit of this approach is the ability to significantly increase the molecular complexity of the product through the introduction of additional ring(s) and stereogenic centers. Moreover, given the significant stereoelectronic difference between the enyne and diene components, it should be possible to suppress the homo-carbocyclization and/or oligomerization. ${ }^{9}$

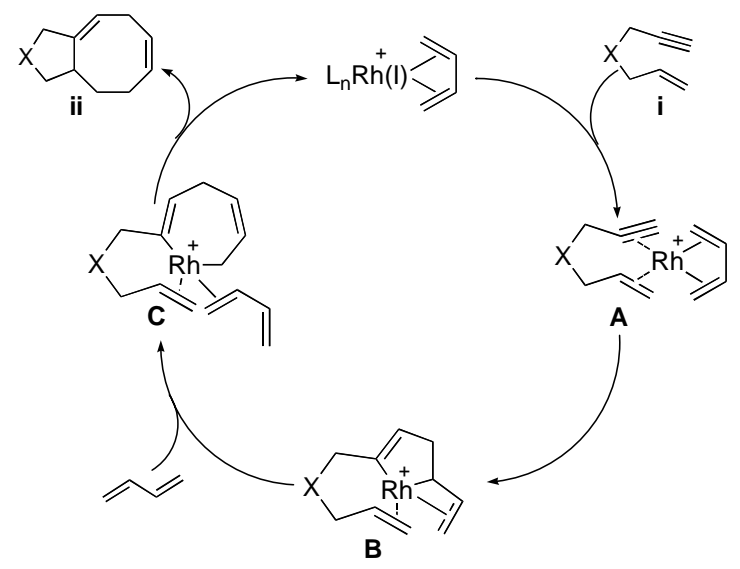

Scheme 1. Proposed catalytic cycle for the rhodium-catalyzed [4+2+2] carbocyclization reaction.

Preliminary studies tested the feasibility of this hypothesis, as outlined in Table 1. Treatment of the 1,6-enyne 7a with Wilkinson's catalyst $\left[\mathrm{RhCl}\left(\mathrm{PPh}_{3}\right)_{3}\right]$ under an atmosphere of 1,3-butadiene in refluxing toluene, furnished a trace amount of 8a (Entry 1), owing to the propensity for the 1,6-enyne 7a to undergo homo-cycloaddition to afford 9a ( $d s \geq 19: 1)$. Gratifyingly, the silver triflate modified rhodium-catalyst, furnished the desired carbocyclization adduct $\mathbf{8 a}$ in $85 \%$ yield (Entry 2). The ability to alter selectivity in this manner prompted additional studies to explore the effect of various silver salts on the carbocyclization (Entries 25). Interestingly, a rather intriguing trend in selectivity emerged from this study. In the extreme case, the hexafluoroantimonate counter-ion completely reverses the selectivity for heterocarbocyclization in the presence of 1,3-butadiene, to afford the homo-dimer 9a in $89 \%$ yield. The origin of this selectivity was attributed to the propensity for these catalysts to promote oligomerization of 1,3-butadiene, thereby reducing its effective concentration. Analysis of the 
crude reactions confirmed this hypothesis, in which the silver triflate modified catalyst lead to the least amount of oligomer and thus explained the origin of the excellent selectivity for the hetero-carbocyclization (Entry 2).

Table 1. Development of the rhodium-catalyzed [4+2+2] cycloaddition reaction ${ }^{\mathrm{a}}$

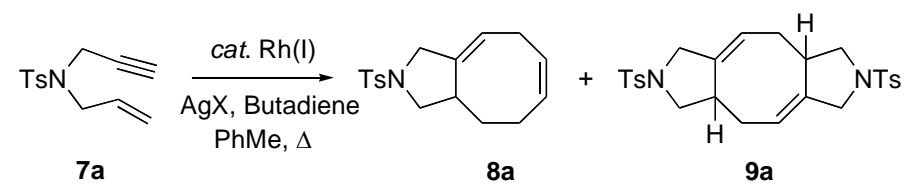

\begin{tabular}{|c|c|c|c|c|}
\hline Entry & Additive $^{\mathrm{b}}$ & $\begin{array}{l}\text { Ratio of } \\
\mathbf{8 a}: \mathbf{9} \mathbf{a}^{\mathrm{c}}\end{array}$ & Yield of $\mathbf{8 a}(\%)^{\mathrm{d}, \mathrm{e}}$ & Yield of $9 \mathbf{a}(\%)^{\mathrm{f}}$ \\
\hline 1 & None & $1: 8$ & $7(0)$ & 57 \\
\hline 2 & AgOTf & $28: 1$ & 85 (4) & 3 \\
\hline 3 & $\mathrm{AgBF}_{4}$ & $11: 1$ & $74(0)$ & 7 \\
\hline 4 & $\mathrm{AgPF}_{6}$ & $2: 1$ & $49(2)$ & 27 \\
\hline 5 & $\mathrm{AgSbF}_{6}$ & $1: 44$ & $2(6)$ & 89 \\
\hline
\end{tabular}

a All reactions were carried out on a $0.5 \mathrm{mmol}$ reaction scale using $10 \mathrm{~mol} \%$ of Wilkinson's catalyst $\left[\mathrm{RhCl}\left(\mathrm{PPh}_{3}\right)_{3}\right]$ in refluxing toluene under an atmosphere of 1,3-butadiene. ${ }^{\mathrm{b}}$ The rhodium catalyst was modified with $20 \mathrm{~mol} \% \mathrm{AgX}$ as indicated. ${ }^{\mathrm{c}}$ Ratios of hetero- and homocycloaddition products were determined by capillary GLC and HPLC on aliquots of the crude reaction mixture. ${ }^{\mathrm{d}}$ GLC yields. ${ }^{\mathrm{e}}$ Yields in parenthesis are for cyclooctadiene. ${ }^{\mathrm{f}}$ HPLC yields.

Table 2 outlines the examination of the influence of various heteroatom tethers and alkyne substitution on the rhodium-catalyzed $[4+2+2]$ carbocyclization. This study demonstrated that nitrogen, sulfur and oxygen containing tethered enynes furnish the corresponding carbocyclization adducts in excellent yield and with analogous selectivity. ${ }^{10}$ The carbocyclization is tolerant of both substituted and unsubstituted alkynes, producing only trace amounts of the enyne cycloisomerization and alkene isomerization products. Moreover, the sulfone tethers provide new substrates for carbocyclization reactions that utilize tethered enynes. 
Table 2. Scope of the intermolecular rhodium-catalyzed $[4+2+2]$ carbocyclization reaction $^{\mathrm{a}}$

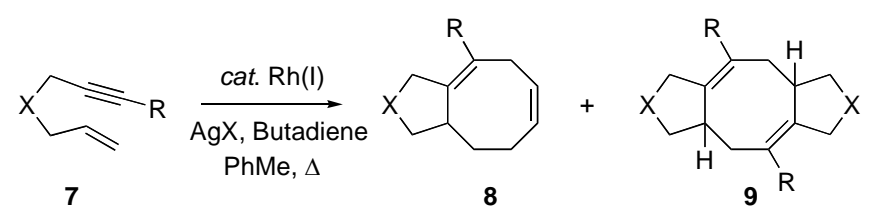

\begin{tabular}{cccccc}
\hline Entry & $\mathrm{X}$ & $\mathrm{R}$ & \multicolumn{2}{c}{${\text { Ratio of } \mathbf{8}: \mathbf{9}^{\mathrm{b}}}$} & Yield of $\mathbf{8}(\mathbf{\%})^{\mathrm{c}}$ \\
\hline $\mathbf{1}$ & $\mathrm{TsN}$ & $\mathrm{H}$ & $\mathbf{a}$ & $\geq 19: 1$ & 91 \\
$\mathbf{2}$ & “ & $\mathrm{Me}$ & $\mathbf{b}$ & $\geq 19: 1$ & 91 \\
$\mathbf{3}$ & “ & $\mathrm{Ph}$ & $\mathbf{c}$ & $\geq 19: 1$ & 87 \\
$\mathbf{4}$ & $\mathrm{SO}_{2}$ & $\mathrm{H}$ & $\mathbf{d}$ & $\geq 19: 1$ & 79 \\
$\mathbf{5}$ & “ & $\mathrm{Me}$ & $\mathbf{e}$ & $\geq 19: 1$ & 73 \\
$\mathbf{6}$ & “ & $\mathrm{Ph}$ & $\mathbf{f}$ & $\geq 19: 1$ & 87 \\
$\mathbf{7}$ & $\mathrm{O}$ & $\mathrm{H}$ & $\mathbf{g}$ & $\geq 19: 1$ & 71 \\
$\mathbf{8}$ & “ & $\mathrm{Me}$ & $\mathbf{h}$ & $\geq 19: 1$ & 81 \\
$\mathbf{9}$ & “ & $\mathrm{Ph}$ & $\mathbf{i}$ & $\geq 19: 1$ & 92 \\
\hline
\end{tabular}

a All reactions were carried out on a 0.5 mmol reaction scale using $10 \mathrm{~mol} \%$ of Wilkinson's catalyst $\left[\mathrm{RhCl}\left(\mathrm{PPh}_{3}\right)_{3}\right]$, modified with $20 \mathrm{~mol} \%$ AgOTf, in refluxing toluene under an atmosphere of 1,3-butadiene. ${ }^{\mathrm{b}}$ Ratios of hetero- and homo-carbocyclization were determined by $400 \mathrm{MHz}{ }^{1} \mathrm{H}$ NMR with the exception of 8a/9a (28:1 by crude GLC/HPLC). ${ }^{\mathrm{c}}$ Isolated yields.

\section{Diastereoselective Rhodium-Catalyzed $[4+2+2]$ Carbocyclization Reactions}

Encouraged by the results in Table 2, we decided to examine the diastereoselective intermolecular rhodium-catalyzed [4+2+2] carbocyclization using a C-2 substituted 1,6-enyne. Preliminary attempts revealed that although the carbocyclization was feasible, the reaction required reduced concentration to suppress unwanted side reactions. Treatment of the enyne 10a $(\mathrm{R}=\mathrm{Np})$ under the optimized reaction conditions $(0.0625 \mathrm{M})$ using silver triflate modified Wilkinson's catalyst, furnished the azabicycles 11a/12a in $91 \%$ yield, as a $\geq 19: 1$ mixture of diastereoisomers favoring 11a (eq 1). The stereochemistry was confirmed by X-ray crystallography, which established the anti-relationship of the protons at C-2/C-3 (as labeled).

In light of the success with the naphthyl substituted 1,6-enyne 10a, we elected to examine other substituents in order to determine the generality of this transformation. ${ }^{6,11,12}$ Surprisingly, the extension of this methodology to other C-2 substituted 1,6-enynes, particularly alkyl derivatives, afforded only trace amounts of the product thus indicating that the original catalyst was highly substrate dependent. For example, treatment of the enyne $\mathbf{1 0 b}(\mathrm{R}=\mathrm{Me})$ with this catalyst in the presence of 1,3-butadiene, afforded only trace amounts of the carbocycle $\mathbf{1 1} \mathbf{b} / \mathbf{1 2 b}$ $(<5 \%)$. 


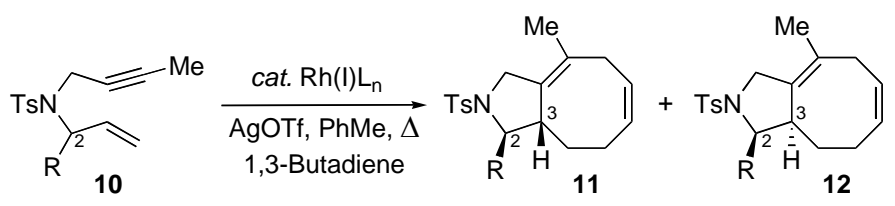

Table 3 summarizes the examination of various precatalysts and ligands in an attempt to develop a more general reaction. Bidentate phosphine ligands were initially explored (Entries 13), which with the exception of ethane-1,2-diylbis(diphenylphosphine) (dppe) (Entry 1), provided analogous results to Wilkinson's catalyst. Various monodentate trialkyl phosphines were also examined, as exemplified by tricyclohexylphosphine and tri- $n$-butylphosphine (Entries 4 and 5), which afforded the desired product as a single diastereoisomer with improved yield. Based on the improved efficiency demonstrated with the electron-rich monodentate ligands, we speculated that strong $\sigma$-donation might be a crucial component for catalytic turnover in this particular reaction.

Table 3. Pre-catalyst/ligand screening for the diastereoselective $[4+2+2]$ carbocyclization of $10 b(\mathrm{R}=\mathrm{Me})^{\mathrm{a}}$

\begin{tabular}{ccccc}
\hline Entry & Pre-catalyst ${ }^{\mathrm{b}, \mathrm{c}}$ & Ligand & $\begin{array}{c}\text { Ratio of } \\
\mathbf{1 1 b}: \mathbf{1 2 b}^{\mathrm{d}}\end{array}$ & Yield $(\%)^{\mathrm{e}}$ \\
\hline $\mathbf{1}$ & {$\left[\mathrm{RhCl}(\mathrm{COE})_{2}\right]_{2}$} & dppe & $\geq 19: 1$ & 34 \\
$\mathbf{2}$ & "“ & $\mathrm{dppp}$ & - & $<5$ \\
$\mathbf{3}$ & "“ & $\mathrm{dppb}$ & - & $<5$ \\
$\mathbf{4}$ & “ & $\mathrm{P}\left({ }^{\mathrm{c}} \mathrm{Hex}\right)_{3}$ & $\geq 19: 1$ & 30 \\
$\mathbf{5}$ & $\mathrm{P}\left({ }^{\mathrm{n}} \mathrm{Bu}\right)_{3}$ & $\geq 19: 1$ & 45 \\
$\mathbf{6}$ & $\mathbf{R h C l ( I M e s ) ( C O D )}$ & - & $\geq \mathbf{1 9 : 1}$ & $\mathbf{7 5}$ \\
\hline
\end{tabular}

${ }^{\mathrm{a}}$ All reactions $(0.25 \mathrm{mmol})$ were carried out in toluene $(0.08 \mathrm{M})$ at $110^{\circ} \mathrm{C} .{ }^{\mathrm{b}} 10 \mathrm{~mol} \%$ of monomer and $5 \mathrm{~mol} \%$ of dimer were employed. ${ }^{\mathrm{c}} 2$ equivalents of AgOTf relative to the metal were utilized. ${ }^{\mathrm{d}}$ Ratios determined by $400 \mathrm{MHz}{ }^{1} \mathrm{H}$ NMR on crude reaction mixtures. ${ }^{\mathrm{e}}$ GLC yields. $(\mathrm{COE}=$ Cyclooctene $)$

$N$-heterocyclic carbene (NHC) ligands are known phosphine surrogates, which fulfill the criterion for strong $\sigma$-donation. Indeed, since the first independent reports of $N$-heterocylic carbene complexes by Wanzlick ${ }^{13}$ and Öfele ${ }^{14}$ and the isolation of the first crystalline NHC by Arduengo, ${ }^{15}$ these carbenes have gained considerable prominence as important ligands in organometallic chemistry. This may be attributed to the fact that these singlet carbenes behave in an analogous manner to amines, ethers, and phosphines as classical $2 \mathrm{e}^{-}$donors, ${ }^{16}$ in which the NHC's serve as better donors than some of the best phosphines. Furthermore, NHC's are often more resistant to dissociation from the metal center in many systems. ${ }^{17}$ As a result, NHC-metal 
complexes have been successfully utilized as catalysts or pre-catalysts for a variety of transition metal-catalyzed transformations. ${ }^{16,18}$ Despite the myriad of transformations utilizing NHC-metal complexes, there are relatively few examples of their use in $[m+n+o]$ carbocyclization reactions. $^{19,20}$

Gratifyingly, the utilization of the rhodium(I) NHC complex, $\mathrm{RhCl}(\mathrm{IMes})(\mathrm{COD})$, provided a remarkable improvement in the overall efficiency of the reaction, in which the cyclooctanoid 11b was obtained in 75\% yield, as a single diastereoisomer (Entry 6). ${ }^{21,22}$ In light of this result, we decided to examine the substrate scope of this catalyst for a variety of C-2 substituted 1,6enynes, since it demonstrated considerable promise as a potential solution to the $[4+2+2]$ reaction and also represents a novel catalyst for carbocyclization reactions.

Table 4. Scope of the diastereoselective [4+2+2] carbocyclization using $\mathrm{RhCl}(\mathrm{IMes})(\mathrm{COD})^{\mathrm{a}}$

\begin{tabular}{|c|c|c|c|c|}
\hline \multirow{2}{*}{$\begin{array}{c}\text { Entry } \\
\mathbf{1}\end{array}$} & \multicolumn{2}{|c|}{$\begin{array}{c}\text { 1,6-Enyne } \mathbf{1 0} \\
\mathrm{R}=\end{array}$} & \multirow{2}{*}{$\begin{array}{c}\text { Ratio of } 11: \mathbf{1 2}^{b} \\
\quad \geq 19: 1\end{array}$} & \multirow{2}{*}{$\begin{array}{c}\text { Yield }(\%)^{c} \\
84\end{array}$} \\
\hline & $\mathrm{Me}$ & b & & \\
\hline 2 & $\mathrm{Bn}$ & c & $\geq 19: 1$ & 79 \\
\hline 3 & $\mathrm{Ph}\left(\mathrm{CH}_{2}\right)_{2}$ & d & $\geq 19: 1$ & 83 \\
\hline 4 & ${ }^{i} \mathrm{Pr}$ & $\mathbf{e}$ & $\geq 19: 1$ & 84 \\
\hline 5 & ${ }^{c}$ Hex & $\mathbf{f}$ & $\geq 19: 1$ & 75 \\
\hline 6 & $\mathrm{HOCH}_{2}$ & $\mathbf{g}$ & $\geq 19: 1$ & 55 \\
\hline 7 & $\mathrm{BnOCH}_{2}$ & $\mathbf{h}$ & $\geq 19: 1$ & 77 \\
\hline 8 & $\mathrm{TBSOCH}_{2}$ & $\mathbf{i}$ & $\geq 19: 1$ & 83 \\
\hline 9 & $\mathrm{CO}_{2} \mathrm{Me}$ & $\mathbf{j}$ & $\geq 19: 1$ & 71 \\
\hline 10 & $\mathrm{CH}_{2}=\mathrm{CH}$ & $\mathbf{k}$ & $\geq 19: 1$ & 81 \\
\hline 11 & $\mathrm{CH}_{2}=\mathrm{CHCH}_{2}$ & 1 & $\geq 19: 1$ & 79 \\
\hline 12 & $\mathrm{Ph}$ & $\mathbf{m}$ & $\geq 19: 1$ & 89 \\
\hline
\end{tabular}

${ }^{\mathrm{a}}$ All reactions $(0.25 \mathrm{mmol})$ were carried out using $10 \mathrm{~mol} \%$ of the catalyst in toluene $(0.08 \mathrm{M})$ at $110{ }^{\circ} \mathrm{C}$. ${ }^{\text {b }}$ Ratios determined by $400 \mathrm{MHz}{ }^{1} \mathrm{H}$ NMR on crude reaction mixtures. ${ }^{\mathrm{c}}$ Isolated yields.

Table 4 summarizes the reactions of various enynes $10 \mathrm{~b}-\mathbf{m}$ with silver triflate modified $\mathrm{RhCl}(\mathrm{IMes})(\mathrm{COD})$ in the presence of excess 1,3-butadiene. In all cases the rhodium-catalyzed $[4+2+2]$ carbocyclization reaction proceeds with excellent diastereocontrol affording the desired carbocyles 10b-m in high yield. This catalytic system works efficiently with various linear and branched alkyl and benzyl substituents at the C-2 position (Entries 1-5). Interestingly, the reaction is also tolerant of a free hydroxyl group, albeit resulting in lower yield (Entry 6). Presumably, the free hydroxyl group's ability to coordinate the metal center is responsible for 
the lower the efficiency of the reaction. In line with this reasoning, protection of the hydroxyl substituent allowed for improved efficiencies (Entry 7-8). Likewise, the catalytic system is tolerant of functional groups such as esters, other olefins, and aryl groups (Entries 9-12).

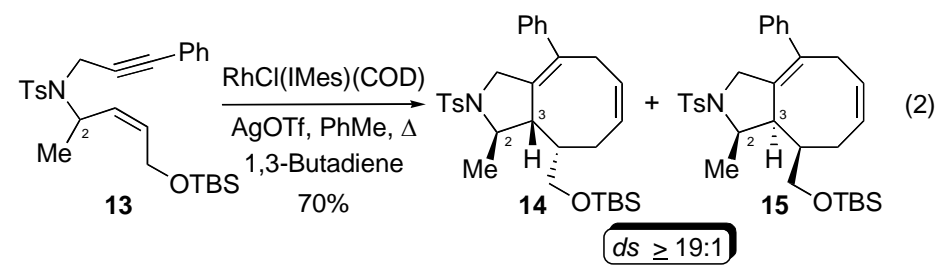

We envisioned that the application of this methodology to substituted alkenes would further highlight the synthetic utility of this catalyst through the introduction of an additional stereogenic center. Moreover, alkene substitution is often poorly tolerated, given that these substrates are prone to enyne cycloisomerization. ${ }^{10}$ Gratifyingly, the treatment of the enyne $\mathbf{1 3}$ under the standard [4+2+2] carbocyclization conditions, using the $\mathrm{RhCl}(\mathrm{IMes})(\mathrm{COD})$ catalyst, furnished the carbocycle $\mathbf{1 4 / 1 5}$ in $70 \%$ yield, with $\geq 19: 1$ diastereoselectivity favoring $\mathbf{1 4}$ (eq 2 ).

\section{Intermolecular Silicon-Tethered Rhodium-Catalyzed $[4+2+2]$ Cycloisomerization Reactions}

Despite the important advances in the intermolecular rhodium-catalyzed [4+2+2] carbocyclization for a series of heteroatom-tethered 1,6-enynes with 1,3-butadiene, additional studies aimed at broadening the scope of this reaction demonstrated that substituted dienes were either unreactive or afforded mixtures of regioisomers. ${ }^{23}$ Hence, we envisioned that tethering the diene to the 1,6-enyne, thereby rendering the process intramolecular, would circumvent problems associated with low reactivity and poor regioselectivity.
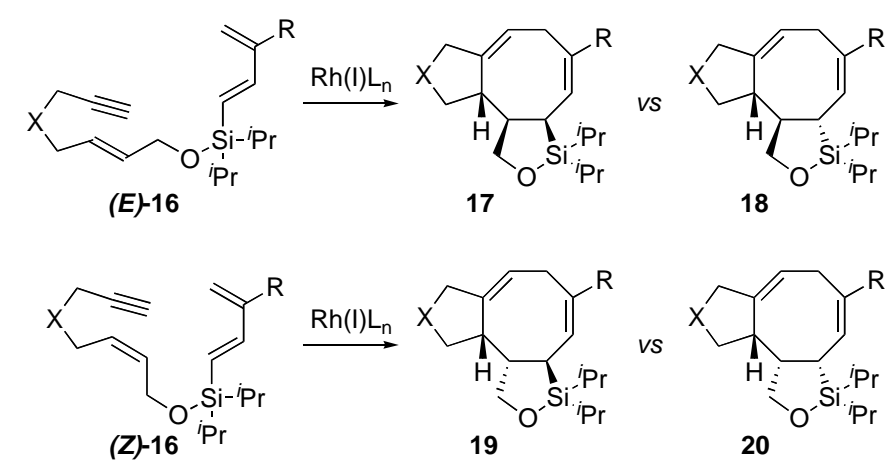

Scheme 2. Intramolecular silicon-tethered rhodium-catalyzed [4+2+2] cycloisomerization 
Since the seminal work of Nishiyama ${ }^{24}$ and $\mathrm{Stork}^{25}$ on the use of "temporary silicon tethers" (TST) in free radical cyclization reactions, this strategy has been employed extensively in target directed synthesis. ${ }^{26}$ The most attractive features of the TST strategy are: i) the reactive components are generally easily tethered, ii) the tethers provide intramolecularity, which render the processes regiospecific and stereoselective, and iii) the tethers incorporate latent functionality that can be further manipulated. Despite the multitude of transformations that have successfully employed a temporary silicon-tether, there remains a paucity of metal-catalyzed carbocyclization reactions employing this strategy. ${ }^{27}$ Nonetheless, we anticipated that application of the TST approach to the rhodium-catalyzed [4+2+2] carbocyclization reaction would provide rapid entry into various polycyclic octanoid derivatives having latent functionality necessary for further synthetic manipulation. Moreover, the inability to incorporate carbon tethers in the intermolecular reaction manifold prompted the reexamination of this tether in the context of the present reaction, viz. intramolecularity of the $\pi$-components. Hence, it was expected that the competing ene-cycloisomerization observed in the intermolecular reaction with carbon-tethered 1,6-enynes would be minimized. ${ }^{10}$

Table 5. Optimization of the temporary silicon-tethered rhodium-catalyzed [4+2+2] cycloisomerization reaction (Scheme $2 ;(Z)-16$ where $X=N T s, R=H)^{\text {a }}$

\begin{tabular}{|c|c|c|c|c|c|}
\hline Entry & Catalyst $^{\mathrm{b}}$ & Additive $^{c}$ & Solvent & $\begin{array}{c}d s^{\mathrm{d}} \\
19 / 20\end{array}$ & Yield $(\%)^{\mathrm{e}}$ \\
\hline 1 & $\mathrm{RhCl}\left(\mathrm{PPh}_{3}\right)_{3}$ & AgOTf & PhMe & - & 0 \\
\hline 2 & $\mathrm{RhCl(IMes)(COD)}$ & “" & “" & - & 0 \\
\hline 3 & “ & $\mathrm{AgSbF}_{6}$ & “" & $\geq 19: 1$ & 18 \\
\hline 4 & {$\left[(\mathrm{COD}) \mathrm{Rh}(\mathrm{Np}) \mathrm{SbF}_{6}\right.$} & - & “ & $\geq 19: 1$ & 30 \\
\hline 5 & {$[(\mathrm{COD}) \mathrm{Rh}(\mathrm{Np})] \mathrm{SbF}_{6}$} & - & $\mathrm{MeCN}$ & $\geq 19: 1$ & 60 \\
\hline
\end{tabular}

${ }^{\mathrm{a}}$ All reactions were carried out on a $0.25 \mathrm{mmol}$ reaction scale at $110{ }^{\circ} \mathrm{C}(0.08 \mathrm{M}) .{ }^{\mathrm{b}} 20 \mathrm{~mol} \% .{ }^{\mathrm{c}} 2$ equivalents of $\mathrm{AgX}$ relative to the metal. ${ }^{\mathrm{d}}$ Diastereoselectivity was determined by $400 \mathrm{MHz}$ NMR on the crude reaction mixtures. ${ }^{\mathrm{e}}$ Isolated yields.

Preliminary studies tested the validity of this hypothesis, as outlined in Table 5. Attempted cycloisomerization of enyne $(Z)-16$ (where $X=N T s, R=H$ ) using the reaction conditions successfully employed for the intermolecular reaction, led to the formation of a complex reaction mixture (Entry 1$)^{6},{ }^{6}$ as did the rhodium- $N$-heterocyclic carbene catalyst (Entry 2). ${ }^{11}$ It is well established that the counter-ion of the silver salt additive is often highly significant in modifying the properties of the active catalytic species to thereby facilitate the requisite carbocyclization reaction. Interestingly, the hexafluoroantimonate counter-ion proved optimum in this regard, which is orthogonal to the trend observed for the intermolecular reaction (Entry 3). ${ }^{6}$ In order to further improve the efficiency and obviate the necessity for an in situ modification of the precatalyst, we elected to examine the Wender catalyst 
$\left([(\mathrm{COD}) \mathrm{Rh}(\mathrm{Np})] \mathrm{SbF}_{6}\right){ }^{28}$ Although this catalyst initially afforded only modest improvement (Entry 4), the efficiency could be dramatically improved using the more coordinating solvent, acetonitrile (Entry 5).

Table 6 summarizes the scope of the intramolecular rhodium-catalyzed [4+2+2] cycloisomerization reaction. This study demonstrated that nitrogen and oxygen tethers could be utilized (Entries 1-8), however, the sulfone tethers (where $\mathrm{X}=\mathrm{SO}_{2}$ ), which were utilized in the intermolecular reaction, proved unsuitable for this particular transformation. Interestingly, not only were the carbon-tethered enynes effective substrates, but they proved to be the most efficient tethers examined (Entries 9-12). This reaction also proceeds efficiently with 1,3disubstituted dienes, thereby circumventing the regiochemical problems associated with the intermolecular version (Entries 2, 4, 6, etc.). ${ }^{23}$ The ability to vary the olefin geometry results in complementary diastereoinduction, in which the $(E)$ - and $(Z)$-olefins are stereospecifically incorporated, to afford the tricyclic octanoids 17 and 19 with excellent selectivity (Entries 1-12). Furthermore, the $(E)$-isomers are superior substrates in terms of efficiency in the cycloisomerization, as compared to their (Z)-counterparts (Entries $1 / 2 \mathrm{vs} \mathrm{3/4} \mathrm{etc.).} \mathrm{Overall,} \mathrm{this}$ method represents one of the most versatile cycloisomerization reactions developed to date.

Table 6. Scope of the regio- and diastereoselective TST rhodium-catalyzed [4+2+2] cycloisomerization with various carbon and heteroatom tethered 1,6-enynes ${ }^{\mathrm{a}}$

\begin{tabular}{|c|c|c|c|c|c|c|}
\hline \multirow[t]{2}{*}{ Entry } & \multicolumn{3}{|c|}{ 1,6-Enyne 16} & \multirow{2}{*}{\multicolumn{2}{|c|}{$d s^{\mathrm{b}, \mathrm{c}}$}} & \multirow{2}{*}{$\begin{array}{l}\text { Yield } \\
(\%)^{\mathrm{d}}\end{array}$} \\
\hline & $X$ & $E / Z$ & $\mathrm{R}$ & & & \\
\hline 1 & NTs & $E$ & $\mathrm{H}$ & 17 & $\geq 19: 1$ & 75 \\
\hline 2 & 6 & 6 & $\mathrm{Me}$ & “ & $\geq 19: 1$ & 85 \\
\hline 3 & “ & $Z$ & $\mathrm{H}$ & 19 & $\geq 19: 1$ & 60 \\
\hline 4 & “ & “ & $\mathrm{Me}$ & 6 & $\geq 19: 1$ & 71 \\
\hline 5 & $\mathrm{O}$ & $E$ & $\mathrm{H}$ & 17 & $\geq 19: 1$ & 73 \\
\hline 6 & 6 & 6 & $\mathrm{Me}$ & “ & $\geq 19: 1$ & 85 \\
\hline 7 & “ & $Z$ & $\mathrm{H}$ & 19 & $\geq 19: 1$ & 39 \\
\hline 8 & “ & “ & $\mathrm{Me}$ & “ & $\geq 19: 1$ & 44 \\
\hline 9 & $\mathrm{C}\left(\mathrm{CO}_{2} \mathrm{Et}\right)_{2}$ & $E$ & $\mathrm{H}$ & 17 & $\geq 19: 1$ & 86 \\
\hline 10 & 66 & “ & $\mathrm{Me}$ & 6 & $\geq 19: 1$ & 88 \\
\hline 11 & 6 & $Z$ & $\mathrm{H}$ & 19 & $\geq 19: 1$ & 71 \\
\hline 12 & 6 & 66 & $\mathrm{Me}$ & 6 & $\geq 19: 1$ & 74 \\
\hline
\end{tabular}

${ }^{a}$ All reactions $(0.25 \mathrm{mmol})$ were carried using $20 \mathrm{~mol} \%$ [(COD)Rh(Np)]SbF 6 in $\mathrm{MeCN}$ at 110 ${ }^{\circ} \mathrm{C}(0.08 \mathrm{M}) .{ }^{\mathrm{b}}$ Diastereoselectivity was determined by $400 \mathrm{MHz} \mathrm{NMR}$ on the crude reaction mixtures. ${ }^{\mathrm{c}}$ The relative configuration of $\mathbf{1 7}$ and $\mathbf{1 9}$ (where $\mathrm{X}=\mathrm{NTs}, \mathrm{R}=\mathrm{Me}$ ) was proven by $\mathrm{X}$ ray crystallography, and related by analogy to the ${ }^{1} \mathrm{H}$ NMR of the other tethers. ${ }^{\mathrm{d}}$ Isolated yields. 
The stereospecificity with respect to the olefin geometry is consistent with the intermolecular case. ${ }^{11}$ Moreover, while the origin of diastereocontrol with respect to the diene is not completely certain, it is consistent with an identical orientation of the diene in each case. This can presumably be attributed to non-bonding interaction between one of the isopropyl groups on silicon, and the protons on the 1,3-butadiene derivative. ${ }^{29}$ The origin of the diastereoselectivity is currently being probed theoretically.

\section{Crossed Intermolecular Rhodium-Catalyzed $[2+2+2]$ Carbocyclization Reactions}

The metal-catalyzed [2+2+2] reaction of a tethered 1,6-diyne has been employed extensively as a tactic for the construction of various natural product skeletons. ${ }^{5}$ Despite the myriad of studies with 1,6-diynes, ${ }^{30,31}$ the crossed intermolecular rhodium-catalyzed $[2+2+2]$ carbocyclization with 1,6-enynes has not been forthcoming. ${ }^{32-34}$

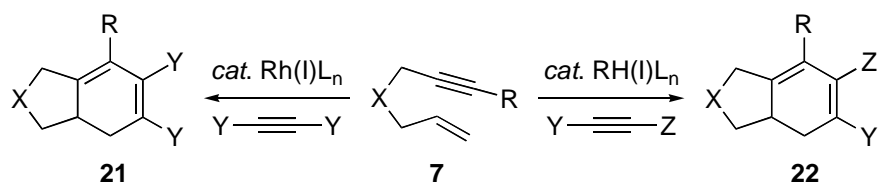

Scheme 3. Crossed intermolecular rhodium-catalyzed [2+2+2] carbocyclization of 1,6-enynes with symmetrical and unsymmetrical alkynes.

We envisioned that this type of carbocyclization would facilitate the rapid increase in molecular complexity, through the ability to introduce stereoelectronically orthogonal alkynes in a selective fashion. Moreover, this strategy would readily access the sesquiterpenes 4-6. ${ }^{35}$

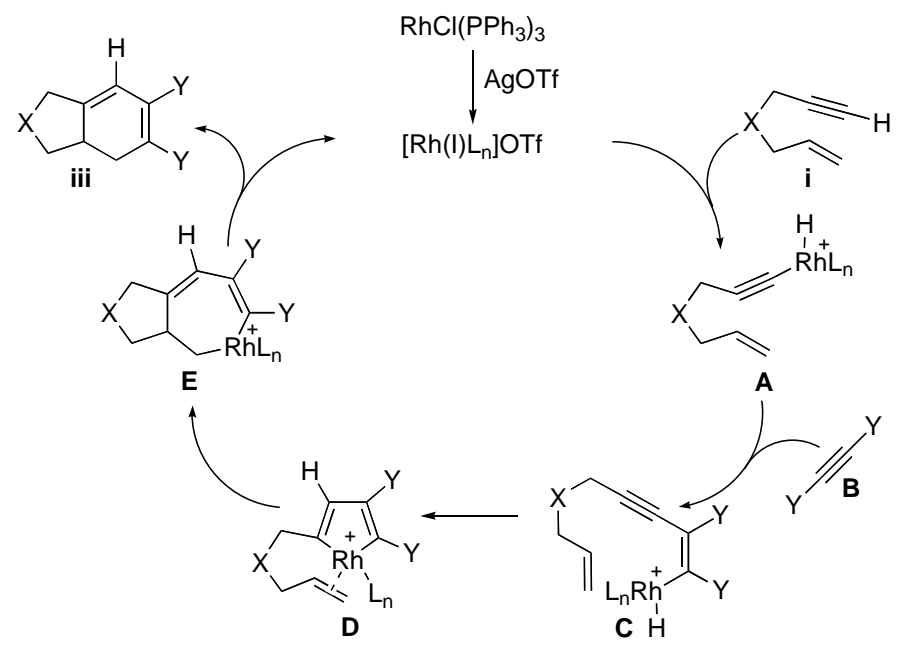

Scheme 4. Proposed catalytic cycle for the rhodium-catalyzed $[2+2+2]$ carbocyclization reaction. 
The mechanistic hypothesis for the desired carbocyclization outlined in Scheme 4, draws from the seminal studies of others. ${ }^{30-32}$ It was anticipated the terminal acetylenic $\mathrm{C}-\mathrm{H}$ bond of the tethered enyne $\mathbf{i}$ should undergo an oxidative insertion to afford $\mathbf{A}$. Coordination of the free alkyne $\mathbf{B}$ followed by hydrometallation should lead to the formation of $\mathbf{C}$, en route to the key metallacyclopentadiene $\mathbf{D}{ }^{36}$ Intramolecular migratory insertion across the tethered alkene, followed by a reductive elimination of metallacycle $\mathbf{E}$, should then afford the $[2+2+2]$ carbocyclization adduct iii. We reasoned that selective intermolecular $[2+2+2]$ carbocyclization would be feasible, since alkyne B should preferentially undergo carbometallation with A, provided the concentration of alkyne $\mathbf{B}$ was such that it would avoid competition with the intramolecular migratory insertion of the alkene in $\mathbf{D}$, or reaction with itself.

Table 7. Development of the rhodium-catalyzed [2+2+2] carbocyclization reaction (Scheme 3; 7a where $\mathrm{X}=\mathrm{NTs}, \mathrm{R}=\mathrm{H}$ and $\left.\mathrm{Y} / \mathrm{Y}=\mathrm{CO}_{2} \mathrm{Me}\right)^{\mathrm{a}}$

\begin{tabular}{|c|c|c|c|c|}
\hline Entry & Conc. (mol/L) & Solvent & Temp. $\left({ }^{\circ} \mathrm{C}\right)$ & Yield $(\%)^{b}$ \\
\hline 1 & 0.10 & $\mathrm{EtOH}$ & 60 & 17 \\
\hline 2 & “" & $\mathrm{MeCN}$ & “6 & 42 \\
\hline 3 & “6 & $\mathrm{PhH}$ & "“ & 80 \\
\hline 4 & 0.50 & “" & "“ & 57 \\
\hline 5 & 0.05 & PhH & 60 & 95 \\
\hline 6 & “" & “" & 40 & 48 \\
\hline 7 & “6 & “6 & 80 & 82 \\
\hline
\end{tabular}

a All reactions were carried out on a $0.25 \mathrm{mmol}$ reaction scale utilizing $10 \mathrm{~mol} \%$ of Wilkinson's catalyst $\left[\mathrm{RhCl}\left(\mathrm{PPh}_{3}\right)_{3}\right]$ modified with $20 \mathrm{~mol} \%$ AgOTf in the presence of dimethyl acetylenedicarboxylate (3 equiv.) under an atmosphere of argon. ${ }^{\mathrm{b}}$ HPLC yield.

Preliminary studies tested this hypothesis by screening various reaction conditions, as outlined in Table 7. Treatment of the enyne 7a $(\mathrm{X}=\mathrm{NTs}, \mathrm{R}=\mathrm{H})$ with silver triflate modified Wilkinson's catalyst in the presence of excess dimethyl acetylenedicarboxylate $\left(\mathrm{Y} / \mathrm{Y}=\mathrm{CO}_{2} \mathrm{Me}\right)$ in ethanol at $60{ }^{\circ} \mathrm{C}$, furnished the bicyclohexadiene 21a in 17\% yield (Entry 1). Additional studies examined the effect of solvent (Entries 1-3), concentration (Entries 3-5), and temperature (Entries 5-7), in an attempt to optimize for the desired carbocyclization reaction. Gratifyingly, the non-coordinating solvent benzene $(0.05 \mathrm{M})$ at $60{ }^{\circ} \mathrm{C}$ proved optimum, affording 21a in 95\% yield (Entry 5). ${ }^{35}$ Interestingly, the homodimerization adduct was not observed, whereas the product resulting from the competitive trapping of the metallacyclopentadiene D with a second equivalent of dimethyl acetylenedicarboxylate was produced in varying amounts, depending upon the concentration. Furthermore, the terminal acetylenic proton of the 1,6-enyne 
7a proved to be crucial for catalytic activity, since the corresponding substituted derivatives, where $\mathrm{R}=\mathrm{Me}$, $\mathrm{Ph}$ or TMS, did not afford any of the carbocyclization adduct. ${ }^{30-35}$

Table 8 outlines the examination of the influence of various tethers and the scope of alkyne substituents that are tolerated. This study demonstrated that nitrogen, carbon, and oxygen containing tethered enynes furnish the corresponding bicyclohexadienes 21a-i in good to excellent yield. Examination of the alkyne scope revealed that the reaction was optimal for the 1,2-disubstituted alkynes bearing electron withdrawing groups, i.e. dimethyl acetylenedicarboxylate, bis-phenyl ketone and bis-dimethylamide, albeit slightly less efficient in the latter case. Interestingly, diphenylacetylene $(\mathrm{Y} / \mathrm{Y}=\mathrm{Ph})$ furnished only a trace amount of the carbocyclization product, thereby confirming the necessity for a strongly electron withdrawing group on the alkyne.

Table 8. Scope of the intermolecular rhodium-catalyzed [2+2+2] carbocyclization reaction (Scheme 3; where $\mathrm{R}=\mathrm{H})^{\mathrm{a}}$

\begin{tabular}{|c|c|c|c|c|c|}
\hline \multirow{2}{*}{$\begin{array}{c}\text { Entry } \\
\mathbf{1}\end{array}$} & \multicolumn{2}{|c|}{$\begin{array}{c}\text { 1,6-Enyne } 7 \\
\mathrm{X}=\end{array}$} & \multicolumn{2}{|c|}{$\begin{array}{c}\text { Bicyclohexadiene } 21 \\
\mathrm{Y}=\end{array}$} & \multirow{2}{*}{$\begin{array}{r}\text { Yield } \\
(\%)^{b}\end{array}$} \\
\hline & TsN & $\mathbf{a}$ & $\mathrm{CO}_{2} \mathrm{Me}$ & $\mathbf{a}$ & \\
\hline 2 & “ & 6 & $\mathrm{COPh}$ & $\mathbf{b}$ & 84 \\
\hline 3 & “ & “ & $\mathrm{CONMe}_{2}$ & c & 61 \\
\hline 4 & $\mathrm{C}\left(\mathrm{CO}_{2} \mathrm{Me}\right)_{2}$ & $\mathbf{b}$ & $\mathrm{CO}_{2} \mathrm{Me}$ & d & 85 \\
\hline 5 & “6 & “6 & $\mathrm{COPh}$ & e & 74 \\
\hline 6 & “ & “ & $\mathrm{CONMe}_{2}$ & f & 54 \\
\hline 7 & $\mathrm{O}$ & c & $\mathrm{CO}_{2} \mathrm{Me}$ & $\mathbf{g}$ & 84 \\
\hline 8 & “ & “ & $\mathrm{COPh}$ & $\mathbf{h}$ & 81 \\
\hline 9 & “ & 6 & $\mathrm{CONMe}_{2}$ & $\mathbf{i}$ & 55 \\
\hline
\end{tabular}

a All reactions were carried out on a $0.25 \mathrm{mmol}$ reaction scale utilizing $10 \mathrm{~mol} \%$ of Wilkinson's catalyst $\left[\mathrm{RhCl}\left(\mathrm{PPh}_{3}\right)_{3}\right]$ modified with $20 \mathrm{~mol} \%$ AgOTf in the presence of the requisite 1,2disubstituted alkyne (3 equiv.) under an atmosphere of argon. ${ }^{\mathrm{b}}$ Isolated yield.

In order to further demonstrate the potential synthetic utility of this transformation and the importance of a terminal alkyne, we elected to examine the regioselective version utilizing an unsymmetrical alkyne (eq 3). Treatment of the 1,6-enyne 23 with methyl propiolate in the presence of Wilkinson's catalyst modified with silver triflate, furnished the azabicycles $\mathbf{2 4 / 2 5}$ in $84 \%$ yield, in a highly regioselective manner ( $\geq 19: 1$ by NMR). ${ }^{37}$ The regioselective outcome for this transformation was confirmed by X-ray crystallographic analysis of 24. 


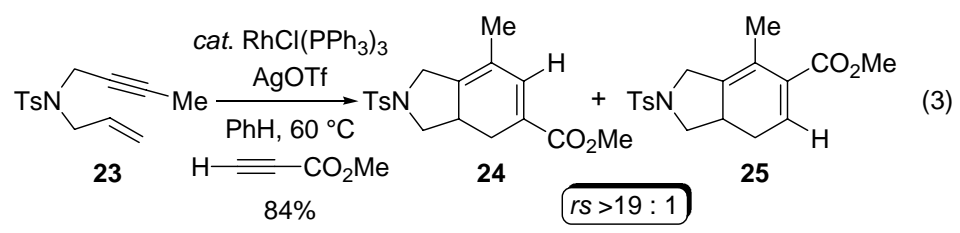

The origin of the excellent regioselectivity can be rationalized by considering the putative metallacycle intermediates, as outlined in Fig. 2. Provided the metallacycle intermediates are formed in an analogous manner outlined in Scheme 4, the 1,6-enyne 23 with methyl propiolate should lead to the formation of I and II, in which II would be unable to undergo the intramolecular carbocyclization due to geometrical constraints. ${ }^{38}$ The efficiency of the carbocyclization and absence of homo-dimerization products is consistent with the notion that either the metallacycle formation is reversible, allowing the equilibration of I and II, or that $\mathbf{I}$ is formed selectively. Additional studies are now underway to provide additional support for this hypothesis.

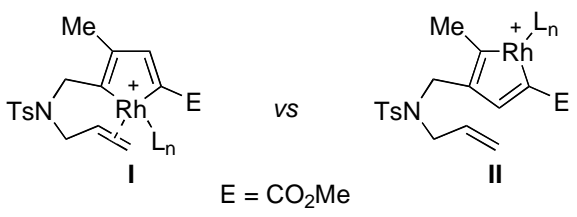

Figure 2. Analysis of the plausible regioisomeric metallacycle intermediates.

\section{Regio- and Enantioselective Intermolecular Rhodium-Catalyzed $[2+2+2]$ Carbocyclization Reactions}

Although the intermolecular metal-catalyzed $[2+2+2]$ carbocyclization reaction of carbon and heteroatom tethered 1,6-enynes with symmetrical 1,2-disubstituted alkynes has been described, a significant challenge with this process is the ability to regioselectively incorporate unsymmetrical 1,2-disubstituted alkynes. ${ }^{5,30-32}$ Furthermore, despite the myriad of metalcatalyzed carbocyclization reactions, the enantioselective version of the metal-catalyzed [2+2+2] carbocyclization of a 1,6-enyne has not been described. In light of these significant challenges, we sought to develop the combined regio- and enantioselective metal-catalyzed $[2+2+2]$ carbocyclization reaction with unsymmetrical 1,2-disubstituted alkynes, and thereby provide a new paradigm for this type of transformation. ${ }^{39}$

Preliminary studies focused on the development of the regio- and enantioselective version of the rhodium-catalyzed [2+2+2] carbocyclization using the 1,6-enyne $7 \mathbf{a}$ as outlined in Table 9. Treatment of 7a with excess methyl phenylpropiolate and the chiral complex derived from silver triflate modified $[\mathrm{RhCl}(\mathrm{COD})]_{2}$ with (S)-BINAP in benzene at $60{ }^{\circ} \mathrm{C}$, furnished the bicyclohexadienes $(\boldsymbol{S})-\mathbf{2 6 a} /(\boldsymbol{S})-\mathbf{2 7} \mathbf{a}$ in $27 \%$ yield as a $2: 1$ mixture of regioisomers (Entry 1). ${ }^{40}$ 
Although the overall efficiency and regioselectivity were not particularly encouraging, the major isomer (S)-26a was obtained with high enantioselectivity $(86 \%$ ee $)$. Previous studies demonstrated that the overall efficiency could be improved dramatically by simply adjusting the nature of the solvent and/or counter-ion. ${ }^{35}$ In light of this fact, we probed the effect of coordinating solvents, and silver salts with progressively weaker coordinating counter ions (Entries 2-5). Gratifyingly, the ethereal solvent tetrahydrofuran in combination with the tetrafluoroborate counter ion proved optimal in terms of efficiency (Entry 5), since these conditions completely suppressed the undesired homo-coupling of 1,6-enyne 7a. Additional optimization focused on the nature of the chiral phosphine ligand to improve and potentially understand the factors that control regioselectivity (see Fig. 1). Interestingly, switching to (S)Xyl-BINAP led to significantly improved regioselectivity (Entry 5 vs. 6). Hence, the more sterically hindered bisphosphine can more effectively discriminate the termini of methyl phenylpropiolate ( $\mathrm{Ph} v$ s. $\mathrm{CO}_{2} \mathrm{Me}$ ). The more $\pi$-acidic (S)-DIFLUORPHOS ligand, which has a narrower dihedral angle than (S)-Xyl-BINAP, furnished the product with diminished regioselection, albeit with higher enantioselectivity (Entry 7). ${ }^{41}$ In accord with this observation, the dipyridyl-phosphines CTH-(S)-P-PHOS and (S)-Xyl-P-PHOS ligands, which possesses a dihedral angle similar to (S)-DIFLUORPHOS, afforded excellent enantioselectivity, in which (S)-Xyl-P-PHOS provided the optimum ligand in terms of regioselectivity (Entry 9). ${ }^{42}$ This trend is analogous with the improvement observed for the switch from the (S)-BINAP to $(S)$ Xyl-BINAP ligand (Entry 5 vs. 6), presumably due to similar reasoning.

Table 10 summarizes the application of the optimized reaction conditions (Entry 9) to the various carbon and heteroatom tethered 1,6-enynes using an array of methyl $p$-substituted arylpropiolates. Interestingly, the carbocyclization reaction is highly enantioselective regardless of the nature of the enyne tether and/or the aryl substituent, whereas the yield and/or regioselectivity are influenced by these parameters. For example, although all the enynes undergo regioselective carbocyclizations, the nature of the tether has a profound influence on the level of regiocontrol $\left(\mathrm{O}>\mathrm{NTs}>\mathrm{C}\left(\mathrm{CO}_{2} \mathrm{Me}\right)_{2}\right)$. Similarly, the overall efficiency and regioselectivity can be directly related to the electronic nature of the aryl substituents. This trend is particularly prominent with carbon tethers (Entries 7-10), whereas regioselectivity and efficiency are somewhat affected in the nitrogen (Entries 2-5) and oxygen tethers (Entries 12-15) respectively. Overall, this work now provides access to previously unknown enantiomerically enriched bicyclohexadienes that are useful synthons for target directed synthesis. 
Table 9. Optimization of intermolecular rhodium-catalyzed $[2+2+2]$ carbocyclization reaction $^{\mathrm{a}}$

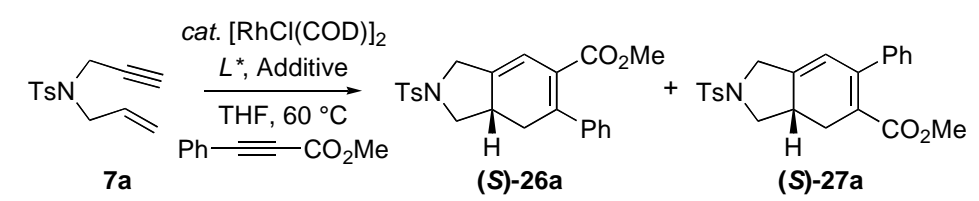

\begin{tabular}{|c|c|c|c|c|c|c|}
\hline Entry & Solvent & Additive & Ligand $\left(L^{*}\right)$ & $\begin{array}{l}\text { Yield } \\
(\%)^{b}\end{array}$ & $r s^{\mathrm{c}}$ & $\begin{array}{c}e e \text { of } \mathbf{2 6 a} \\
(\%)^{\mathrm{d}, \mathrm{e}}\end{array}$ \\
\hline 1 & $\mathrm{PhH}$ & AgOTf & (S)-BINAP & 27 & $2: 1$ & 86 \\
\hline 2 & $\mathrm{MeCN}$ & “ & “6 & 0 & - & - \\
\hline 3 & $\mathrm{THF}$ & “6 & “ & 68 & $3: 1$ & 92 \\
\hline 4 & “ & $\mathrm{AgSbF}_{6}$ & “ & 82 & $3: 1$ & 89 \\
\hline 5 & “ & $\mathrm{AgBF}_{4}$ & “ & 95 & $3: 1$ & 92 \\
\hline 6 & “ & “ & (S)-Xyl-BINAP & 93 & $8: 1$ & 88 \\
\hline 7 & “ & “ & (S)-DIFLUORPHOS & 73 & $4: 1$ & 97 \\
\hline 8 & “ & “ & (S)-P-PHOS & 75 & $5: 1$ & 97 \\
\hline 9 & THF & $\mathrm{AgBF}_{4}$ & (S)-Xyl-P-PHOS & 98 & $10: 1$ & 97 \\
\hline
\end{tabular}

a All reactions were carried out on a $0.25 \mathrm{mmol}$ reaction scale utilizing the chiral complex derived from $5 \mathrm{~mol} \%$ of $[\mathrm{RhCl}(\mathrm{COD})]_{2}$ and $12 \mathrm{~mol} \%$ of the bidentate phosphine ligand, further modified with $20 \mathrm{~mol} \% \mathrm{AgX}$ in the presence of methyl phenylpropiolate (3 equiv.) under an atmosphere of argon. ${ }^{\mathrm{b}}$ Isolated yields. ${ }^{\mathrm{c}}$ Regioselectivity was determined by $400 \mathrm{MHz}{ }^{1} \mathrm{H} \mathrm{NMR}$ on the crude reaction mixtures. ${ }^{\mathrm{d}}$ Enantiomeric excess of the major regioisomer 26a was determined by chiral HPLC analysis. ${ }^{\mathrm{e}}$ The regioselectivity and absolute configuration of (S)26a were established by NOESY and X-ray crystallography respectively.

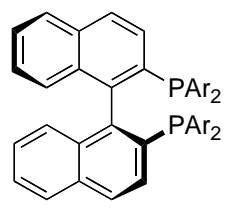

(S)-BINAP: $\mathrm{Ar}=\mathrm{C}_{6} \mathrm{H}_{5}$ (S)-Xyl-BINAP: $\mathrm{Ar}=3,5-\mathrm{Me}_{2} \mathrm{C}_{6} \mathrm{H}_{3}$

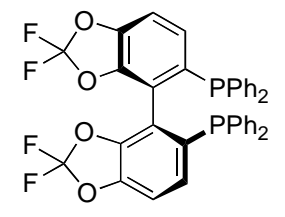

(S)-DIFLUORPHOS

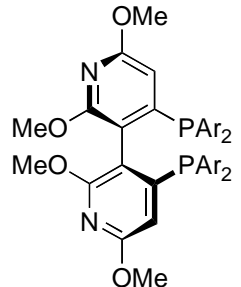

(S)-P-PHOS: $\mathrm{Ar}=\mathrm{C}_{6} \mathrm{H}_{5}$ (S)-Xyl-P-PHOS: $\mathrm{Ar}=3,5-\mathrm{Me}_{2} \mathrm{C}_{6} \mathrm{H}_{3}$

Figure 3. Chiral ligands used in the optimization studies. 
Table 10. Scope of the regio- and enantioselective rhodium-catalyzed [2+2+2] carbocyclization reaction $\left(\mathrm{Ar}=p-\mathrm{FG}-\mathrm{C}_{6} \mathrm{H}_{4}\right)^{\mathrm{a}}$

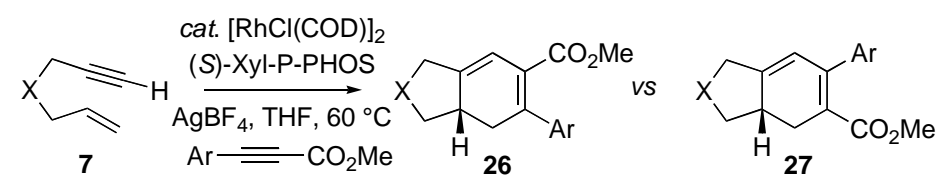

\begin{tabular}{|c|c|c|c|c|c|c|c|}
\hline Entry & $\begin{array}{c}\text { 1,6-Enyne } 7 \\
\mathrm{X}=\end{array}$ & & $\begin{array}{c}\text { Alkyne } \\
\text { FG }=\end{array}$ & \multicolumn{2}{|c|}{$\begin{array}{l}\text { Yield } \\
(\%)^{b}\end{array}$} & $\begin{array}{c}r s \\
(26: 27)^{\mathrm{c}}\end{array}$ & $\begin{array}{c}e e \text { of } 26 \\
(\%)^{d}\end{array}$ \\
\hline 1 & TsN & $\mathbf{a}$ & $\mathrm{H}$ & 98 & $\mathbf{a}$ & $10: 1$ & 97 \\
\hline 2 & “6 & 6 & $\mathrm{OMe}$ & 84 & $\mathbf{b}$ & $14: 1$ & 97 \\
\hline 3 & “6 & 6 & $\mathrm{Me}$ & 95 & c & $11: 1$ & 97 \\
\hline 4 & “6 & 6 & $\mathrm{~F}$ & 87 & d & $10: 1$ & 97 \\
\hline 5 & “" & 6 & $\mathrm{CF}_{3}$ & 86 & $\mathbf{e}$ & $10: 1$ & 98 \\
\hline 6 & $\mathrm{C}\left(\mathrm{CO}_{2} \mathrm{Me}\right)_{2}$ & $\mathbf{b}$ & $\mathrm{H}$ & 88 & $\mathbf{f}$ & $9: 1$ & $\geq 99$ \\
\hline 7 & “6 & 6 & $\mathrm{OMe}$ & 85 & $\mathbf{g}$ & $10: 1$ & 98 \\
\hline 8 & “ & 6 & $\mathrm{Me}$ & 80 & $\mathbf{h}$ & $9: 1$ & 95 \\
\hline 9 & “ & 6 & $\mathrm{~F}$ & 74 & $\mathbf{i}$ & $7: 1$ & 98 \\
\hline 10 & “" & 6 & $\mathrm{CF}_{3}$ & 65 & $\mathbf{j}$ & $5: 1$ & 98 \\
\hline 11 & $\mathrm{O}$ & c & $\mathrm{H}$ & 86 & $\mathbf{k}$ & $\geq 19: 1$ & $\geq 99$ \\
\hline 12 & “ & 6 & $\mathrm{OMe}$ & 95 & 1 & $\geq 19: 1$ & 98 \\
\hline 13 & “" & 6 & $\mathrm{Me}$ & 87 & m & $\geq 19: 1$ & 98 \\
\hline 14 & “ & 6 & $\mathrm{~F}$ & 75 & $\mathbf{n}$ & $17: 1$ & $\geq 99$ \\
\hline 15 & “ & 6 & $\mathrm{CF}_{3}$ & 72 & $\mathbf{0}$ & $17: 1$ & 97 \\
\hline
\end{tabular}

a All reactions were carried out on a $0.25 \mathrm{mmol}$ reaction scale utilizing the chiral complex derived from $5 \mathrm{~mol} \%$ of $[\mathrm{RhCl}(\mathrm{COD})]_{2}$ and $12 \mathrm{~mol} \%$ of $(S)$-Xyl-P-PHOS, further modified with $20 \mathrm{~mol}^{\circ} \mathrm{AgBF}_{4}$ in the presence of methyl arylpropiolate (3 equiv.) under an atmosphere of argon.. ${ }^{\mathrm{b}}$ Isolated yields. ${ }^{\mathrm{c}}$ Ratio of regioisomers was determined by $400 \mathrm{MHz}{ }^{1} \mathrm{H}-\mathrm{NMR}$ on the crude reaction mixtures. ${ }^{\mathrm{d}}$ Enantiomeric excess of the major regioisomer was determined by chiral HPLC analysis.

In order to further demonstrate the scope of this transformation, we elected to examine an alternative electron-withdrawing group within the alkyne. Treatment of the 1,6-enyne 7a under the optimized reaction conditions with 4-phenyl-3-butyn-2-one, furnished the bicyclohexadienes 29a/30a $(\mathrm{R}=\mathrm{H})$ in $86 \%$ yield, with $\geq 19: 1$ regioselectivity and $95 \%$ ee for 29a (eq 4). Additionally, we envisioned the application of this methodology to a substituted 1,6-enyne 28 ( $R$ $=\mathrm{Me}$ ) would facilitate the enantioselective introduction of a quaternary carbon stereogenic center, which would be a particularly attractive feature of this methodology. ${ }^{43}$ Gratifyingly, treatment of $\mathbf{2 8}$ under the optimized carbocyclization conditions with 4-phenyl-3-butyn-2-one, 
furnished the quaternary substituted bicyclic azacycles $29 \mathrm{~b} / 30 \mathrm{~b}(\mathrm{R}=\mathrm{Me})$ in $84 \%$ yield, with 10:1 regioselectivity and $\geq 99 \%$ ee for $\mathbf{2 9 b}$.

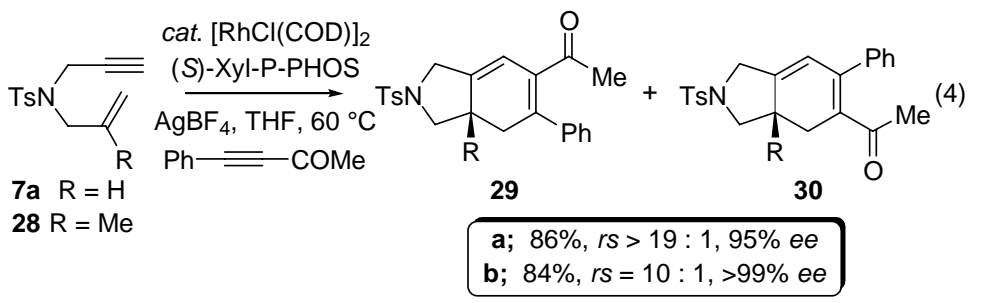

In conclusion, we have developed a series of rhodium-catalyzed [4+2+2] and [2+2+2] carbocyclization reactions that address chemo- and stereoselectivity for the construction of complex polycyclic skeletons that are applicable to various natural products. Additional studies on the development and application of this novel methodology to the total synthesis of natural products are currently underway in the group.

\section{Acknowledgments}

We sincerely thank the National Institutes of Health (GM58877) and the National Science Foundation (CHE-0316689) for generous financial support. We also thank the Division of Organic Chemistry of the American Chemical Society for a Graduate Fellowship (JER) sponsored by Eli Lilly, Roche Pharmaceuticals for an Excellence in Chemistry Award (EWB) and Pfizer GRD for a Fellowship Supporting Diversity in Organic Chemistry (ANF).

\section{References}

1. For lead references on the isolation of 1-6, see: (a) 1. San Feliciano, A.; Barrero, A. F.; Medarde, M.; Miguel del Corral, J. M.; Aramburu, A. Tetrahedron Lett. 1985, 26, 2369. (b) 2. Adesomoju, A. A.; Okogun, J. I.; Cava, M. P.; Carroll, P. J. Phytochemistry 1983, 22, 2535. (c) 3. Enoki, N.; Furusaki, A.; Suehiro, K.; Ishida, R.; Matsumoto, T. Tetrahedron Lett. 1983, 24, 4341. (d) 4/5. Porter, L. A. Chem. Rev. 1967, 67, 441. (e) 6. Okuda, T.; Yoshida, T. Tetrahedron Lett. 1971, 12, 4499.

2. For recent reviews on metal-mediated cyclooctanoid construction, see: (a) (b) Sieburth, S. McN.; Cunard, N. T. Tetrahedron 1996, 52, 6251. (b) Mehta, G.; Singh, V. Chem. Rev. 1999, 99, 881. (c) Yet, L. Chem. Rev. 2000, 100, 2963.

3. For recent reviews on metal-catalyzed carbocyclization reactions, see: (a) Aubert, C.; Buisine, O.; Malacria, M. Chem. Rev. 2002, 102, 813. (b) Nakamura, I.; Yamamoto, Y. Chem. Rev. 2004, 104, 2127. 
4. Robinson, J. E. In Modern Rhodium-Catalyzed Organic Reactions; Evans, P. A. Ed.; WileyVCH: Weinheim, 2005, Ch. 12, p 241.

5. For recent reviews on metal-mediated [2+2+2] carbocyclizations, see: (a) Malacria, M.; Aubert, C.; Renaud J. L. In Science of Synthesis: Houben-Weyl Methods for Molecular Transformations; Lautens, M.; Trost, B. M. Eds.; Georg Thieme Verlag: New York, 2001; Vol 1, pp 439-530. (b) Varela, J.; Saá, C. Chem. Rev. 2003, 103, 3787. (c) Fujiwara, M.; Ojima, I. In Modern Rhodium-Catalyzed Organic Reactions; Evans, P. A. Ed.; Wiley-VCH: Weinheim, 2005; Ch. 7, p 129 and pertinent references cited therein.

6. (a) Evans, P. A.; Robinson, J. E.; Baum, E. W.; Fazal, A. N. J. Am. Chem. Soc. 2002, 124, 8782. (b) Evans, P. A.; Robinson, J. E.; Baum, E. W.; Fazal, A. N. J. Am. Chem. Soc. 2003, $125,14648$.

7. For another example of a rhodium(I)-catalyzed [4+2+2] carbocyclizations see: Gilbertson, S. R.; DeBeof, B. J. Am. Chem. Soc. 2002, 124, 8784.

8. For related metal-catalyzed [4+2+2] carbocyclizations reactions, see: (a) Greco, A.; Carbonaro, A.; Dall'Asta, G. J. Org. Chem. 1970, 35, 271. (b) Carbonaro, A.; Cambisi, F.; Dall'Asta, G. J. Org. Chem. 1971, 36, 1443. (c) Lautens, M.; Tam, W.; Lautens, J. C.; Edwards, L. G.; Crudden, C. M.; Smith, A. C. J. Am. Chem. Soc. 1995, 117, 6863. (d) Varela, J. A.; Castedo, L.; Saá, C. Org. Lett. 2003, 5, 2841.

9. The rhodium-catalyzed cycloisomerization of 1,3-butadiene is known to favor oligomerization rather than the formation of cyclooctadiene, see: Bosch, M.; Brookhart, M. S.; Ilg, K.; Werner, H. Angew. Chem., Int. Ed. 2000, 39, 2304.

10. Although the carbocyclization proceeds with heteroatom tethers, the carbon derivatives lead to mixtures, in which enyne cycloisomerization was the major adduct. For a rhodiumcatalyzed version, see: Cao, P.; Wang, B.; Zhang, X. J. Am. Chem. Soc. 2000, 122, 6490.

11. Evans, P. A.; Baum, E. W.; Fazal, A. N.; Pink, M. Chem. Commun. 2005, 63.

12. For a detailed discussion of the mechanism and origin of diastereoselectivity, see Baik, M.H.; Baum, E. W.; Burland, M. C.; Evans, P. A. J. Am. Chem. Soc. 2005, 127, 1602.

13. Wanzlick, H.-W.; Schönherr, H.-J. Angew. Chem., Int. Ed. 1968, 7, 141.

14. Öfele, K. J. Organomet. Chem. 1968, 12, P42.

15. Arduengo, A. J.; Harlow, R. L.; Kline, M. J. Am. Chem. Soc. 1991, 113, 361.

16. For recent review on $N$-heterocyclic carbenes, see: Herrmann, W. A. Angew. Chem., Int. Ed. 2002, 41, 1290.

17. (a) Huang, J.; Stevens, E. D. Nolan, S. P. Organometallics 2000, 19, 1194. (b) Chianese, A. R.; Li, X.; Janzen, M. C.; Faller, J. W.; Crabtree, R. H. Organometallics 2003, 22, 1663.

18. (a) Hillier, A. C.; Nolan, S. P. Platinum Metals Rev. 2002, 46, 50. (b) Trnka, T. M.; Grubbs, R. H. Acc. Chem. Res. 2001, 34, 18.

19. For an example of a rhodium(I) NHC-catalyzed hydrosilylation/cyclization of 1,6-enynes, see: Park, K. H.; Kim, S. Y.; Son, S. U.; Chung, Y. K. Eur. J. Org. Chem. 2003, 4341.

20. (a) For an example of Ni-NHC catalyzed [2+2+2] cycloaddition, see: Louie, J.; Gibby, J. E.; Farnworth, M. V.; Tekavec, T. N. J. Am. Chem. Soc., 2002, 124, 15188. (b) For an example 
of Co-NHC catalyzed Pauson Khand reaction, see: Gibson, S. E.; Johnstone, C.; Loch, J. A.; Steed, J. W.; Strevenazzi, A. Organometallics 2003, 22, 5374.

21. Seayad, A. M.; Selvakumar, K.; Ahmed, M.; Bellar, M. Tetrahedron Lett. 2003, 44, 1679.

22. For a saturated version of the NHC catalyst, see: Denk, K.; Sirsch, P.; Herrmann, W. A. J. Organomet. Chem. 2002, 649, 219.

23. Evans, P. A.; Baum, E. W. J. Am. Chem. Soc. 2004, 126, 11150.

24. Nishiyama, H.; Kitajima, T.; Matsumoto, M.; Itoh, K. J. Org. Chem. 1984, 49, 2298.

25. Stork, G.; Kahn, M. J. Am. Chem. Soc. 1985, 107, 500.

26. For recent reviews on TST strategies, see: (a) White, J. D.; Carter, R. G. In Science of Synthesis: Houben-Weyl Methods of Molecular Transformations; Fleming, I., Ed.; Georg Thieme Verlag: New York, 2001; Vol. 4, p 371. (b) Skrydstrup, M. In Science of Synthesis: Houben-Weyl Methods of Molecular Transformations; Fleming, I., Ed.; Georg Thieme Verlag: New York, 2001; Vol. 4, p 439 and pertinent references therein.

27. For examples of metal-mediated and metal-catalyzed TST carbocyclization reactions, see: (a) Kagoshima, H.; Hayashi, M.; Yukihiko, H.; Saigo, K. Organometallics 1996, 15, 5439. (b) Brummond, K. M.; Sill, P. C.; Rickards, B.; Geib, S. J. Tetrahedron Lett. 2002, 43, 3735. (c) Chouraqui, G.; Petit, M.; Aubert, C.; Malacria, M. Org. Lett. 2004, 6, 1519 and references cited therein.

28. Wender, P. A.; Williams, T. J. Angew. Chem., Int. Ed. 2002, 41, 4550.

29. (a) Sieburth, S. McN.; Fensterbank, L. J. Org. Chem. 1992, 57, 5279. (b) Evans, P. A.; Cui, J.; Buffone, G. P. Angew. Chem., Int. Ed. 2003, 42, 1734.

30. For pioneering work on the rhodium-catalyzed intermolecular $[2+2+2]$ carbocylization using tethered 1,6-diynes and 1,6-enynes, see: (a) Grigg, R.; Scott, R.; Stevenson, P. J. Chem. Soc., Perkin Trans. 1 1988, 1357. (b) Grigg, R.; Scott, R.; Stevenson, P. J. Chem. Soc., Perkin Trans. 1 1988, 1365.

31. For some recent examples of intermolecular rhodium-catalyzed [2+2+2] carbocyclizations of tethered 1,6-diynes, see: (a) McDonald, F. E.; Zhu, H. Y. H.; Holmquist, C. R. J. Am. Chem. Soc. 1995, 117, 6605. (b) Witulski, B.; Stengel, T. Angew. Chem., Int. Ed. 1999, 38, 2426. (c) Nishiyama, H.; Niwa, E.; Inoue, T.; Ishima, Y.; Aoki, K. Organometallics 2002, 21, 2572. (d) Kinoshita, H.; Shinokubo, H.; Oshima, K. J. Am. Chem. Soc. 2003, 125, 7784 and pertinent references cited therein.

32. For a recent example of a rhodium-catalyzed [2+2+2] dimerization of 1,6-enynes, see: Oh, C. H.; Sung, H. R.; Jung, S. H.; Lim, Y. M. Tetrahedron Lett. 2001, 42, 5493.

33. For examples of an intermolecular metal-catalyzed [2+2+2] carbocyclization with various 1,6-enynes using symmetrical alkynes, see: (a) Pd: Trost, B. M.; Tanoury, G. J. J. Am. Chem. Soc. 1987, 109, 4753. (b) Ir: Kezuka, S.; Okado, T.; Niou, E.; Takeuchi, R. Org. Lett. 2005, 7, 1711.

34. (a) Ohshita, J.; Furumori, K.; Matsuguchi, A.; Ishikawa, M. J. Org. Chem. 1990, 55, 3277.

(b) Field, L. D.; Ward, A. J.; Turner, P. Aust. J. Chem., 1999, 52, 1085.

35. Evans, P. A.; Sawyer, J. R.; Lai, K. W.; Huffman, J. C. Chem. Commun. $2005,3971$. 
36. For a trans-hydrometalation with rhodium, see: (a) Tanaka, K.; Fu, G. C. J. Am. Chem. Soc. 2001, 123, 11492. (b) Tanaka, K.; Fu, G. C. Angew. Chem., Int. Ed. 2002, 41, 1607.

37. For an example of a intermolecular cobalt-mediated $[2+2+2]$ carbocyclization with various 1,6-enynes using an unsymmetrical alkyne, see: Chang, C.-A.; King, Jr., J. A.; Vollhardt, K. P. C. J. Chem. Soc., Chem. Commun. 1981, 53.

38. For an example of complementary regiochemistry in metallacycle formation, see: Tanaka, K.; Shriasaka, K. Org. Lett. 2003, 5, 4697.

39. Evans, P. A.; Lai, K. W.; Sawyer, J. R. J. Am. Chem. Soc. 2005, 127, 12466.

40. For excellent review on the development of chiral bisphosphine ligands, see: Shimizu, H.; Nagasaki, I.; Saito, T. Tetrahedron 2005, 61, 5405 and pertinent references cited therein.

41. (a) Jeulin, S.; Duprat de Paule, S.; Ratovelomanana-Vidal, V.; Genêt, J.-P.; Champion, N.; Dellis, P. Angew. Chem. Int. Ed. 2004, 43, 320.

42. (a) Pai, C.-C.; Lin, C.-W.; Lin, C.-C.; Chen, C.-C.; Chan, A. S. C.; Wong, W. T. J. Am. Chem. Soc. 2000, 122, 11513. (b) Wu, J.; Chen, H.; Kwok, W.; Guo, R.; Zhou, Z.; Yeung, C.; Chan, A. S. C. J. Org. Chem. 2002, 67, 7908.

43. For recent reviews on the enantioselective construction of quaternary carbon stereocenters, see: (a) Christoffers, J.; Mann, A. Angew. Chem., Int. Ed. 2001, 40, 4591. (b) Denissova, I.; Barriault, L. Tetrahedron 2003, 59, 10105 and pertinent references cited therein. 